To the Editors:

\title{
Immune response to hepatitis B vaccination in a group of medical students in
}

\section{Sri Lanka}

\author{
F Noordeen ${ }^{1}$, D G C S Madushanka ${ }^{2}$, F N N Pitchai ${ }^{1}$
}

Ceylon Medical Journal 2016; 61: 46 http://doi.org/10.4038/cmj.v61i1.8267

Hepatitis B virus (HBV) infection poses a serious occupational threat to risk groups like health care workers (HCW) [1]. Studies indicate that the risk of acquiring HBV is four times higher in HCWs compared to non-HCW [2]. $\mathrm{HBV}$ prevalence among $\mathrm{HCW}$ is ten times that of individuals in the general population [2]. The main mode of transmission of HBV among HCW in a clinical setting is through needle stick injuries or cuts and abrasions coming into direct contact with infected body fluids. Infection may also occur by indirect contact via contaminated fomites such as table tops, bedding and clothing [1]. About 6 to $14 \%$ of HCW develop clinical HBV infection from needle prick injuries of HBV surface antigen (HBsAg) positive patients [1].

Routine pre-exposure vaccination is mandatory for HCW and other high risk groups. Despite the vaccination, a number of studies indicate that a minority of individuals (2-10\%) remain non-responsive to the vaccine with immunity below protective levels (anti-HBs $<10 \mathrm{mIU} / \mathrm{ml}$ ) [3]. Such non-responders among HCW are at risk of contracting HBV infection. Identification and revaccination of such individuals are important in order to prevent HBV infection among HCW [4].

The current study involved 90 vaccinated medical students aged 22 to 25 years from the Faculty of Medicine, University of Peradeniya. All had received three doses of $\mathrm{HBV}$ vaccine within the same time period. Data such as age, sex, ethnicity, date of vaccination, current medication and presence of any liver disease or dysfunction were collected. Blood samples were taken approximately eight weeks after their last dose of the vaccination. Serum was subjected to an ELISA (ANTISURASE B-96-TMB, Taiwan) to assess anti-HBs levels. Data obtained from the ELISA and questionnaires were analysed using SPSS statistical software and Microsoft Excel 2010. Approval for the study was obtained from the Ethics Committee of the Faculty of Medicine, University of Peradeniya.

Of the 90 participants, 55 were females. All participants had absorbance values above the calculated cut off value for protection indicating anti-HBs levels over $10 \mathrm{mIU} / \mathrm{mL}$. This suggests protective levels of immunity.

None of the participants had blood transfusions, needle prick injuries, intravenous drug use or unprotected sexual intercourse in the past. Thus, it was assumed that any immunity acquired was by vaccination and not due to previous exposure to $\mathrm{HBV}$. According to the WHO, the HBV vaccine (Euvax, Korea) produces protective immunity in more than $95 \%$ of vaccinated adults and this is in agreement with the results of our study in which the protective immunity achieved was 100\% [3]. HBV vaccination is known to provide long term protection that lasts for several years. According to previous studies immunised individuals had anti-HBs levels above $100 \mathrm{mIU} / \mathrm{ml}$ even after 14 years of their last vaccination [5]. The most plausible reason for $100 \%$ protective immunity in our study cohort would be the participants' age. Immune response to the HBsAg vaccine is poor in those above 30 years of age. Poor immune response to HBV vaccination has been shown to increase from $2.8 \%$ in individuals at the age of 30 to $4.2 \%$ in individuals at the age of 40 [3].

\section{References}

1. Mast EE, Alter MJ. Prevention of hepatitis B virus infection among health-care workers. In: Ellis RW, Ed. Hepatitis B vaccines in clinical practice. Marcel Dekker Inc: West Point 1993; 295-307.

2. Mahoney FJ, Stewart K, Hu H, Coleman P, Alter MJ. Progress toward the elimination of hepatitis $\mathrm{B}$ virus transmission among healthcare workers in the United States Arch Intern Med 1997; 157: 2601-5.

3. Roome AJ, Walsh SJ, Carter ML, et al. Hepatitis B vaccine responsiveness in Connecticut public safety personnel JAMA 1993; 270: 2931-4.

4. Rosea E, Rudensky B, Pez E. Ten years follow up study of hepatitis B Virus infection and vaccination status in hospital employee $J$ Hosp Infec 1999; 41: 245-50.

5. Chathuranga LS, Noordeen F, Abeykoon AMSB. Immune response to hepatitis B vaccine in a group of health care workers in Sri Lanka. Int J Infect Dis 2013; 17: 1078-9.

${ }^{1}$ Department of Microbiology, ${ }^{2}$ Faculty of Medicine, University of Peradeniya, Sri Lanka.

Correspondence: FN, e-mail: <faseeha.noordeen12@gmail.com>. Received 16 September and revised version accepted 12 December 2015. 